\author{
Robert DMUCHOWSKI
}

\title{
DETERMINANTS OF BUSINESS CLUSTER DEVELOPMENT
}

\begin{abstract}
Business clusters are a new theory and idea of companies' functioning, regardless of the kind of business they do or their market shares. Cluster initiatives are a business phenomenon because they are able to combine, and most importantly, to bring benefits to both small and large companies. Organizations with large resources as well as those that do not have a sufficiently large potential are able to cooperate in order to create mutual benefits, increase their competitiveness and obtain better financial results. The impulse for creating business clusters in a region is caused by the need to broadly support innovation and cooperation of business entities with scientific research and local government institutions in order to achieve common socio-economic benefits for the region.
\end{abstract}

\section{Key words:}

Business clusters, innovation, competitive advantage, efficiency.

JEL: F23, F61, O31.

(C) Robert Dmuchowski, 2020.

Dmuchowski Robert, Dr., University of Computer Science and Economics TWP in Olsztyn, Poland. ORCID: https://orcid.org/0000-0003-1681-3463 Email: rdmuchowski@wp.pl. 


\section{Introduction}

At the turn of the 20th and 21st centuries, many countries began to create instruments focused on business clusters to strengthen their economic capabilities in terms of innovation and increasing regional and national competitiveness. As part of creating instruments that support innovation, establishment of networks between business, research centres and development institutes plays an important role and has a huge impact on the success of such activities. Cluster initiatives are an appropriate and effective instrument for concentrating resources and measures accelerating the transfer of knowledge and know-how to achieve a competitive advantage. Currently, regions and regional enterprises are facing the challenges created by the global market. A region's competitiveness is not determined by individual enterprises, but by innovative activities of entire industries and branches. The need to create business clusters in a region was driven by the need to broadly support innovation, cooperation and internationalization of business ventures. The ability to increase innovation is a determining factor for the success of regions, and the increasing use of information technology puts great emphasis on accelerating innovation processes. Clusters' tasks in supporting cooperation in a region include building links within industry, with particular emphasis on small and medium-sized enterprises, research institutes and academic centres. Support for cooperation projects increases the share of processes related to innovation and technology transfer from research and development institutions and scientific centres to industry. Creating clusters also provides opportunities for cooperation on the global market, especially for SMEs that do not have sufficient resources and know-how to enter new markets. Therefore, internationalization has become an essential factor for businesses and regions to succeed in global competition.

Prospects for the potential benefits of cluster initiatives for enterprises and regions encourage local authorities and other public partners to implement policies to promote economic clusters because participation in clusters allows gaining an advantage in spotting new technical, operational and delivery opportunities. Companies and research centres quickly and systematically obtain information about the progress in technology, the availability of components and machines as well as various logistic, marketing or service concepts. A welldeveloped concentration of related business activities should ensure increased productivity (through specialized expenditure, access to information, synergy and access to public goods), increased innovation (through joint research and more intense competition) and creation of new enterprises (filling niches and expanding cluster boundaries).

The main determinant of business clusters development is the possibility of faster economic development for enterprises, and also the opportunity to in- 
ISSN 2519-4070

crease the competitiveness and efficiency of the entire region through their cooperation with non-economic organizations.

The article aims to present the main factors influencing establishment of cluster initiatives in regions.

\section{Clusters as tools for increasing competitiveness of enterprises}

The competitiveness of a company, region and nation depends on its ability to raise the level of its competition. Competitiveness in the current economic reality is something obvious. Benefits are obtained due to the existence of rivals with whom one has to compete constantly and more effectively by producing products or services that are recognized by potential buyers (product innovation) and by producing products at the lowest cost and of high quality so that it is possible to achieve higher profitability of an enterprise and maximize profits (process and organizational innovation). Competitiveness means that all rivals can benefit, provided they are innovative. Companies gain an advantage over the best competitors (other companies) as a result of exerting pressure on them and challenges. Benefits are also obtained by subcontractors, suppliers of primary and semi-finished products as well as recipients of finished products, because they all compete with one another for limited opportunities offered by the market. Monopolistic position or lack of competition between business entities means that the economy and society do not develop and profits are achieved by few. State institutions should not support or help in any way individual entities to achieve better economic and financial results. Rather, their role should be to stimulate a good climate, economic and social environment and to spread innovation. Differences in values, culture, economic structures, and institutions contribute to success in competition. The best benefits are achieved by the businesses and regions that operate or will operate in environments that create optimal conditions for competition for them, are dynamic and pose the highest challenges. The best economic effects are achieved by enterprises and regions that apply strategies, which differ in every respect. Companies achieve competitive advantage through innovative activities. They strive for innovation in the broadest sense of the word, change product and technology and use new procedural methods. They see a new basis for competing or improve existing ways of competition. It should also be mentioned that innovations can contribute to gaining a competitive advantage by finding opportunities, market niches and economic areas that potential competitors have not noticed or appreciated. The competitive advantage obtained thanks to innovations still needs to be fostered and improved, because each competitive advantage can be imitated and, undoubtedly, competitors do it. Almost all managers and heads of authorities at all levels are aware of the impact 
of innovation on competitiveness and development of an enterprise and the region. The problem that arises concerns the ways of acquiring the necessary resources and eliminating any obstacles to implementing systematic innovative initiatives.

An innovative company will be the basic entity to guarantee the region's development. Each enterprise should be provided with equal conditions for conducting business activity and competitiveness of each of these enterprises will depend on their knowledge, propensity for risk, investment and wise effective decisions. However, regional authorities can support these companies in their pursuit of development by removing barriers and allowing them to innovate.

In order to achieve and maintain a competitive advantage, companies must recognize the importance of innovation in economic processes that results primarily from pressure and challenges posed by competitors, but also the environment in which they operate, e. g. in economic clusters. The external environment, including local institutions and organizations, plays a significant role in the functioning of a company in terms of quality and competitiveness. A large number of effective economic entities means investments, creation of new jobs, development of scientific centres, diffusion of knowledge, and technology transfer a guarantee of the socio-economic development of the region. Therefore, regional and local government authorities have long been looking for the most effective methods to stimulate the development of the region. The best results, as the experience of recent years show, are achieved through multi-dimensional, formal systems and informal networking relationships. They provide a company with opportunities to create, acquire and implement innovativeness as a result of cooperation of a wide range of organizations and institutions operating in a given region. In addition to enterprises, the benefits of this type of cooperation are also achieved by institutions that form a network system, which can be called a cluster. Cluster initiatives arise from independent companies and institutions creating and supplying knowledge (universities, research institutes, technology companies), intermediate institutions (e.g. banks, public institutions) and customers.

Clusters occur in various sectors, in larger and smaller areas, and even in some local areas of activity: window production, local treatment plant, sausage production. Clusters are economic and social initiatives and exist in both developed and developing economies. Clusters differ in size, scope and level of development. Some are made up primarily from small and medium-sized enterprises, others include large and small companies. Some clusters are focused around universities conducting research, while others have no connection with research centres. Higher development clusters have more specialized supplier bases, a wider range of related sectors and more supportive institutions. Task areas of clusters also change along with the development of the economy because new industries and sectors appear and local institutions and legal regulations change. The question may be asked on why the current economic processes increasingly are analysed through the prism of clusters rather than individ- 
ual enterprises, sectors or branches of the economy. First of all, clusters are currently seen (mainly by regions, but and also by enterprises) as the best forms of management, allowing to achieve competitive advantage and guaranteeing the development not only of individual entities but entire regions. In addition, cluster initiatives capture important connections, complementarities and the flow of technology, skills, information and marketing as well as the needs of customers, crossing the boundaries of companies and sectors. The presented connections inherent in the internal and external structure of clusters ensure competitiveness and efficiency for all cluster participants. Organizations forming a cluster do not compete with each other directly and, if there is any competition, it is because of earlier constructive cooperation and it benefits all parties. Clusters are an efficient forum for dialogue between related companies and their suppliers, authorities and other important institutions. Public and private investments aimed at improving the conditions of group functioning bring benefits to many companies (Porter, 2001, p. 256)

Clusters affect three ways of gaining a competitive advantage: increasing the efficiency of companies, increasing their ability to innovate, encouraging the creation of new companies.

Clusters in increasing the efficiency of companies (conditions of production factors). A cluster, through its structure, has the ability to accumulate the necessary expenditure for production or service activities efficiently and effectively, i.e. means and objects of work. Obtaining supplies from cluster participants leads to lower costs, minimizing the need to store inventory, eliminating import costs, reducing transaction costs and waiting times. Supplying within a cluster facilitates communication, reduces the costs of adapting to specific needs and facilitates the joint provision of auxiliary or support services, such as installation of devices, removal of defects, training, timely repairs. In addition, supplying «on-site» brings greater benefits compared to suppliers located a long distance away from a company, especially in case of advanced technical, information or service outlays. Clusters also provide benefits in acquiring a qualified workforce. They gain higher efficiency in this respect, because they more efficiently and effectively secure the needs of human resources, use common databases, conduct joint professional trainings, have an appropriate training and research base, which they adapt to changing market needs. Cluster efficiency is also associated with the collection of necessary specialist information that can be used by cluster participants for more efficient business operations. Clusters are conducive to increasing efficiency not only through acquisition and joining expenses, but also by facilitating mutual complementarity in the activities of their participants. The most obvious form of this is the complementarity of products or processes. Coordination and internal mutual pressures influence the improvement and increase of cluster efficiency, improve its quality and operational efficiency. Internal complementarity gives greater benefits to cluster participants than resorting to formal alliances. Due to the fact that cluster initiatives are most often inspired by public institutions, clusters have the possibility of better and more complete access to 
public institutions and the use of public goods. The examples of these are the possibilities of training employees by social institutions or access to specialized infrastructure, which significantly eliminates the company's costs.

Clusters in promoting and implementing innovations (demand conditions). Clusters' ability to innovate also fosters the efficiency of the entire organization. Companies in clusters are able to see the new needs of buyers faster, due to the fact that they are close to a group of companies that know buyers and maintain relations with them, closer to specialized entities that generate information and closer to sophisticated buyers. Participation in clusters allows gaining an advantage in perceiving new technical, operational and delivery opportunities. The structure of a cluster means that all entities must strive to conduct their business based on systematic introduction of innovation. Companies that are afraid of the risk of innovation are «forced» by the environment to stand out in a creative way and at the same time can count on their help, e.g. in the field of training, acquisition of new technologies, use of research centres and granted loans.

Clusters in creating new companies (strategy, structure and competition of companies). High competitiveness between business entities and sectors means that starting new companies comes with barriers that either already exist or appear. Philosophy of cluster functioning as well as the institutions and organizations that create them favour the creation of enterprises and joining them in cluster initiatives. Public institutions are interested in new investments because new jobs are created, while enterprises can cooperate and compete with other companies and benefit directly and indirectly from their resources and thus strengthen cluster investment and competitive advantage over rivals. However, the condition of participation in a cluster is to meet certain requirements, e.g. innovation and competitiveness. The most frequently created companies can be classified as small or medium-sized enterprises. Such companies often have good business ideas but they lack the necessary potential to run business. Efforts to function in a given sector may not be possible due to some barriers. On the other hand, entering a cluster is burdened with much smaller barriers, it is easier to gather the resources, skills and expenditures needed to create an enterprise, which are often at disposal of a cluster and can be used by a new enterprise.

While building cluster initiatives, a strategy and a vision of their actions are created, which are directed at particularly important areas, thanks to which it is possible to improve the competitiveness of entities forming a cluster. All organizations participating in this undertaking determine what will constitute the main strength of the cluster: knowledge, scale of benefits, cooperation with suppliers, acquisition of new technologies, experience of companies, resources and institutions supporting these initiatives. Gaining a competitive advantage by enterprises is possible thanks to the environment in which it operates as it provides a company with opportunities and abilities to entrepreneurship, specialization, acquisition of innovation and diversity of action strategy based on coordination and trust. 
The source of competitive advantage of enterprises participating in clusters are the possibilities of the local environment. Therefore, five necessary features that are characteristic for cluster companies should be distinguished as necessary conditions (Skawińska, 2009, p. 173):

1) spatial concentration of entities competing with each other in a region,

2) concentration of companies within one sector or several similar ones,

3) informal and formal cooperation of enterprises and local institutions as well as horizontal and vertical organizations (networking),

4) specialization of entities in a cluster,

5) flow of knowledge as well as technology and innovation between entities forming clusters.

\section{Determinants of business cluster development}

Business clusters are a new theory and idea of the companies' functioning, no matter what activity they do and what market shares they have. Cluster initiatives are a kind of business phenomenon because they are able to combine, and most importantly, bring benefits to both small and large companies. Organizations with large resources as well as those that do not have the potential are able to work together in order to develop mutual benefits, increase their competitiveness and achieve better financial results. In addition, cluster initiatives are joined by institutions and centres that are not strictly economic but rather social organizations, and which see opportunities for their own development and development of an entire region in joint ventures with business entities. The global market economy has changed the conditions and opportunities to compete. Functioning on a competitive market can be guaranteed by companies, not only those that are able to use their potential professionally, rationally and effectively, but also business entities that are additionally innovative in their operation. The development of technology and fast flow of information mean that products as well as ways and methods of their production have a short life span. Therefore, it is no longer enough to do something perfectly in business operations in terms of organization of production, transport, execution time, but to do it in a way different from what has been done before and differently than our competitors do. Clusters are a form of organization that is based on cooperation with modern technologies, new technical thought and new solutions. Therefore, among the institutions forming a cluster are universities, scientific and technical centres and entities with capital for innovative programmes. 
It can therefore be safely said that innovations are a driving force behind the establishment and development of clusters. In recent years, the overwhelming majority of economists and managers have recognized the role that innovative activities can play in the development of business entities and national economy. Therefore, on the one hand, there is a need to look for funds and resources that could be managed from various areas of economic activity and allocated for broadly understood innovation. On the other hand, these resources should be directed only where they bring the expected effects and the synergy effect is achieved, i.e. interaction, dissemination and spread of innovation. Clusters, by definition, are an ideal organization for such activities and are part of the nationwide concept of economic development through implementation of innovation.

A very important factor of energetic local competition and changes in its system was the transformation process of the Polish economy and the transition to a market economy. This process required a thorough reconstruction of the economic and business entities that functioned as part of this structure. Competition had to move from low salaries to low total costs, which resulted in increased production efficiency and services provision. Over time, these changes become insufficient and enterprises wanting to grow were had to and still have to diversify their activities. Competition must move from imitation to innovation and from small investments to a high level of investment, not only in material resources but also immeasurable, such as skills and technology. Clusters have become an ideal way of connecting new development challenges and supporting enterprises in their implementation into economic reality.

Poland's accession to the EU requires the implementation of various development programmes that support efficiency, innovation and competitiveness. As part of cohesion policy, the focus is on (Klamut, 2011, p. 9):

- improving the efficiency of investment allocation and increasing the effectiveness of public interventions in terms of sustainable support and harmonious development of regions,

- the need to introduce a territorial dimension in the process of implementing other public policies (e.g. industrial),

- the need to improve coordination of an existing coherence policy as well as between it and other community policies,

- focus on unlocking development processes through a more complete use of competitive advantage and development potential of all regions, not just underdeveloped ones.

The new strategy «Europe 2020» indicates that for the next ten years the basic source of economic growth should be building a knowledge-based economy, modern and innovative, and one of the most important priorities in member states should be shaping human resources towards the development of new qualifications on the labour market and their better adaptation to the challenges 
determining development. Actions building human capital should be implemented by investing in education, development of scientific research and making up for technological backwardness in case of countries adapting to the EU level. Poland should implement the objectives of cohesion policy as well as the objectives of the Lisbon Strategy; one of the ways of conducting such activities is state and regional policy in the field of cluster initiatives.

It is also worth focusing on conditions for creating clusters in Poland. This is particularly related to the financial resources that Poland receives from the EU to adapt our economy to EU conditions. The budget for 2014-2020 recently approved by the European Parliament provides enormous financial resources of 106 billion EUR over seven years, including 73 billion EUR for cohesion policy. The vast majority of the funds are intended to be used to increase the competitiveness of the economy and thus reduce unemployment, and broadly understood, innovation should become a tool for these activities. Polish companies, unfortunately, are not innovative and take last places in various innovation classifications. In the field of innovation, Poland held $21^{\text {st }}$ position in 2006 among 25 European Union countries and $27^{\text {th }}$ among 33 OECD countries (Skawińska, 2009, p. 159). Adopting the envisaged measures and, more importantly, meeting the required criteria is not easy, especially for small and medium-sized enterprises. Therefore, cluster initiatives are also aimed at meeting these challenges, reducing the technological gap and dependence of local communities on the economic situation. This creates opportunities to reduce the negative effects of market globalization by creating new places in a cluster and increasing revenues. Local authorities create a good climate for the functioning of all economic entities to facilitate development of a region. They try to obtain the largest possible EU funds by presenting viable development programmes that guarantee the future effective functioning of local business entities, in line with the challenges of the modern global economy. Clusters constitute such local development programmes.

A regional cluster is designed to use all the socio-economic values located in a region, because the dispersion of potential into individual entities does not bring owners expected results as in the case of combining these resources in order to develop higher competitiveness for all participants of the organization. The main partners in clusters are SMEs, which constitute a majority among business entities in Poland. They increase their competitive position in a regional market: labour market, material and financial factors of production, sale of goods and services as well as the investment market and the international market. The competitiveness of SMEs will depend on their competitive cost advantage and flexibility as well as their sources. Maintaining and increasing competitive advantage by enterprises in a cluster is possible primarily thanks to its collective, synergistic ability to use and disseminate economic information and create innovations. Cluster's strength lies in the possibility of conducting a joint scientific and technical policy, in the development of production factors and impact on the legal system. In addition to a bottom-up initiative resulting from SME entrepreneurship 
aimed at creating clusters, external support defined by micro-regional policy and activities of institutions that associate companies is very important. An economic initiative implemented mainly on the basis of SMEs means that there is a large social capital in Poland and Polish society is entrepreneurial. However, high competition in the markets means that only SMEs are able to cope with this competition by providing products to market niches. These are products or services that do not require specialized technology. They are not very technologically advanced. The main problem of the development of our companies is the lack of innovation and capital. Acceptance of EU assistance in the case of SMEs is also associated with a barrier of having their own capital and infrastructure to implement a selected economic programme. A cluster initiative creates a partnership of various organizations, including para-banks, created on the initiative of local authorities and research centres. Local loan and guarantee funds secure the necessary financial capital, which is collected for specific purposes, and funds come from national or local sources. Typically, these are grants and lowinterest loans for start-ups, and in the case of existing companies, these can be non-returnable loans or loans with guarantees. Local authorities may provide access to infrastructure or industrial complexes that exist there as well as to research and development centres, whose task is to support entities operating in a cluster, mainly in the field of consulting and obtaining innovation. SMEs more and more often use external sources of resources and competences - which are direct foreign investments- to overcome development restrictions. They are material and long-term in nature, which means that their goal is a long period of cooperation. Foreign direct investment allows increasing company's tangible assets (needed for SME development), human capital and intangible elements.

In recent years, it has been noticed that the inflow of foreign investments is decreasing in the share of SME capital in manufacturing activities, and the sectors of technologically advanced industries are increasing. The inflow of foreign investment can improve a local business environment and create opportunities for companies to increase their skills in the process of competition and cooperation by formal and informal associations. This allows companies to form clusters and create a local competitive advantage. This is conducive to the transformation of competitive advantages by companies from costly, based on raw and labourintensive products, to quality resulting from the use of new technologies. However, experience shows that to develop businesses based on modern technology investments, a company also needs the ability to create own in time. By definition, business clusters have such absorption capabilities. The foreign capital transfer initiative is related to entrepreneurial activities on the demand and supply side. The interest of foreign investors in a given area is determined by the degree of its investment attractiveness, including the existence of clusters. Clusters can be a good magnet to attract such investments because they have the most entrepreneurial companies in their structures; they emphasize the need for development based on innovation and higher competitiveness, and create conditions for adopting EU funds and foreign direct investment. Attracting foreign investors 
to local communities is particularly beneficial because it causes a cumulative effect and contributes to building a competitive local advantage. One foreign entity placing its investments, e.g. in a cluster, has a double effect, on the one hand, it provides the most technologically advanced potential, on the other hand, if the project is successful, it extends cooperation with cluster participants (other industry companies, research centres) to other sectors operating from country of origin of the investment. At this point, it is also necessary to mention not only the economic benefits, but also the promotional benefits of a cluster, with the possibilities of expanding cooperation.

The driving force of a cluster's dynamic is an entrepreneurial company that creates conditions for acquiring foreign direct investment. The increase in profitability of all cluster entities induces other companies to operate in the environment of this business, and maybe in the structures of already functioning cluster. The demand for various services and cooperation is increasing, so business environment is developing, which through partner relations affects innovation, position of companies, entrepreneurship of a region and new skills. Cooperation initiated in this way should be supported by local and national authorities, adjusting regulations and policies to the challenges of the market.

Cluster initiatives may therefore be a solution to Polish economic problems and contribute to building larger organizations that are usually more effective, innovative and most importantly competitive. The main attributes of establishing business clusters are (Skawińska, 2009, p. 176):

- $\quad$ occurrence of strong socioeconomic relationships between companies and members of households that develop together in the process of adaptation to changes in the environment,

- geographical concentration of enterprises with specialized production in a specific area,

- concentration of independent SMEs around companies specialized in one element of the production process or in the final process,

- the existence of network relationships between enterprises and institutions derived from shared values respected by families and institutions such as the value of work or saving money.

Another determinant of business cluster development is social capital, which perhaps is one the most important, although difficult to measure. It is defined as «norms and social relations embedded in social structures enabling people to coordinate activities and achieve desired goals.» The high level of social capital, which affects economic growth and its development, determines the wealth of a given society in a region or country. Social capital is essential in business and in making economic decisions as:

- condition of efficiency of economic and management systems, 
- condition of entrepreneurship,

- condition for development of a network of companies and clusters,

- cooperation and coordination skills,

- condition of factor productivity,

- market order concept,

- factor affecting the labour market,

- element of adopting the concept of a specific type of market economy,

- a tool shaping organizational culture and the transformation process.

Social capital is a condition of economic processes as an instrument of their support, i. e. the production and reproduction of economic capital. As external changes and above all technological progress accelerate, the importance of competitiveness and innovation makes it difficult to predict economic and social effects and, at the same time, the importance of this capital for the development of region and country is becoming more and more significant. Therefore, social capital may be a condition conducive to or hindering the formation of business clusters. If in a given region there is an appropriate climate for conducting business activity created by local authorities, as well as there is a suitable social climate (trust, mutual understanding, relevant norms and social relations, shared values, education, knowledge, participation, solidarity, entrepreneurship and innovation propensity) various economic initiatives are then created. These initiatives are designed to generate additional economic value and thus increase the well-being of society. Such an economic initiative, resulting from good social capital can be a business cluster.

In addition, the creation of clusters was designed to bring economic effects such as economies of scale, reducing transaction costs and ensuring competition in a global market economy for business entities, supporting institutions and organizations and the region. There are four sources of agglomeration benefits (Gorynia, 2008, p. 31)

- internal economies of scale associated with the production technique or production function of an individual enterprise,

- location benefits, which are a manifestation of the industry's impact on a single enterprise,

- the benefits of urbanization, which are based on the size of the economy in a given region and are external to industry and companies,

- links between industries related to the exchange of goods, closeness to component suppliers, which reduces the prices of these resources. 
Internal economies of scale for an enterprise operating in a cluster are primarily increased competitive opportunities resulting from innovation and strategic differences. Increased supply of products and services and higher efficiency of business processes, including the rate of improvement and innovation, contribute to reducing total costs and thanks to increased sales, benefits in the form of higher profitability ratios are obtained. Clusters also give investment opportunities. Thanks to the funds obtained from a region and outside a region, it is possible to maximize economic benefits and develop production activities. Companies obtain internal benefits of the scale because they incur smaller unit costs in relation to the potential and resources involved. This is related to employee training, acquiring new technologies, knowledge and providing companies in a cluster with access to public socio-economic infrastructure. The functioning of a cluster provides external economies of scale. A characteristic feature of external economies of scale is that they are an industry-specific resource that can be created when companies in the same industry locate their activities in the same region. The effect of external economies of scale is the reduction of unit costs in each industry company when the number of enterprises in that industry in the region increases. Positive external effects arise from locating companies that carry out identical or similar activities nearby. Attractiveness of a given location attract new entities. Cluster's benefits are the results of interactions between economies of scale that generate growing revenues, transport costs, "geographical transaction costs" (costs incurred due to the distance from business partners) and the potential of a region.

The existence of strong network connections between companies forming clusters contributes to reducing (in some clusters very significantly) transaction costs. Companies entering into relationships and further forming a network often jointly develop knowledge and develop a «common language of communication», which translates into the amount of transaction costs. In the global economy, business interactions and various supporting organizations is something obvious, they must therefore bear all sorts of costs of this type that could be called generally "spatial costs of interacting». The amount of transaction costs, especially in some industries, may induce their managers to locate companies near their trading partners. Managers' decisions will depend on the extent to which the product, service or activity undertaken by the company is sensitive to a distance factor. Thanks to connections and interactions, cost reduction, which encourages enterprises to form clusters, not only reduces transport costs and costs of labour change, but also contributes to reducing the costs of obtaining information and knowledge. It can therefore be assumed that transaction costs related to the exchange of goods and services are clearly reduced when there are strong social ties between entities located in geographical proximity.

Globalization, which manifests itself in the progressive harmonization of markets, and thus deregulation and liberalization of international flows of goods and services and production factors, the progressing technical and procedural standardization and the expanding international range of protection of intellectual 
property rights, increases the importance of the company's immediate environment for its market success. Friendly local environment is of particular importance for strengthening the competitiveness of enterprises. Unfortunately, Polish companies are not leaders in terms of competitiveness; the main reason for this situation is their low innovation and associated efficiency. Local authorities wanting to increase the chances of economic rivalry for their enterprises, look for solutions in accordance with the rules of market economy and the adopted EU policy strategy. The best way to rationalize business operations by enterprises, increase their efficiency and profitability, and thus the standard of living of the society in a region is to create clusters. For a given location to become more effective, for its ability to improve products and processes to increase, and for innovation to be introduced, clusters must expand. Otherwise, the natural tendency to increase local costs cannot be counteracted and production will be moved to other areas where lower factor costs or higher subsidies will be offered. An additional argument for creating local clusters is firstly to help regional companies survive in the global market, and then help them to develop and gain an ever higher advantage and competitive position with the investment in science, new technologies, new ways of acquiring customers. Otherwise, the natural tendency to increase local costs cannot be counteracted and production will be moved to other areas where lower factor costs or higher subsidies will be offered.

Clusters, as experience shows, also give the opportunity to start-up companies in a region that is friendly to them and «attract» other external companies, which in turn is beneficial for creating new jobs. In this way, double benefits are obtained: social and economic for regional development.

\section{Conclusions}

There are various determinants of joining individual entities into cluster initiatives. One of the barriers to the development of enterprises, especially SMEs, is the lack of capital to start a business, purchase modern technology, licenses or necessary production factors. The main participants of clusters in the area of practical business activity are micro enterprises and SMEs. They are flexible and developmental, they can adapt to changing economic and social conditions, but they are unable to implement their ideas into business, as they do not have adequate scientific, material and financial potential. Scientific and research institutions, universities see their success in the possibility of cooperation and creating new values with business entities conducting business activities and practical participation in new innovative projects. The acquired knowledge allows them to make their scientific programmes more real, to create new technologies, patents, inventions and skills based on market needs and their practical application. New resources or innovations needed by business entities should be provided by research centres operating in a region. Their activities and research results should 
be closely related to business, and the value and reputation of universities should depend on the ideas implemented in practice and on inventions. Local governments usually initiate the creation of clusters, as they support socio-economic development and allow the use of existing opportunities and resources of the region. Public interventions are necessary for initiating, consulting, financing and ensuring at least a certain level of organizational support for cluster initiatives.

Cluster initiatives are usually undertaken by local authorities and industrial leaders of a given region. They decide about the «driving force» of a cluster and all business projects are created around them. Cluster initiatives are part of a broader strategy to improve the business efficiency of a region and create a good climate for economic and social development, ensuring prosperity for society and the profitability of business ventures for entrepreneurs.

\section{References}

1. Christensen C. (1999). The Innovators Dilemma. Harvard Business Press, Boston.

2. Cohen D., Prusak I. (2001). In Good Company. Harvard Business School Press, Boston.

3. Dmuchowski R., Szmitka St. (2015). The importance of competitiveness and innovation of enterprises in the development of the region, WSliE TWP, Olsztyn. (in Polish)

4. Gorynia M. (2008). Clusters and international competitiveness and internationalization of the enterprise, Difin, Warszawa. (in Polish)

5. Klamut M. (2011). Competitiveness and cohesion in the European Union's development policy, UE, Wrocław. (in Polish)

6. Luchko M., Szmitka S., Dmuchowski R. (2019). Start-up as an innovative economic entity. Galician Economic Bulletin, TNTU, 60(5), pp. 16-26. (in Ukrainian)

7. Luchko M. (2019). Bussines Risk in Changing Dynamics of Global Village: monograph. Publishing House of University of Applied Sciences in Nysa. pp. 89-97.

8. Porter M. (2001). Porter on Competition, PWE, Warszawa. (in Polish)

9. Skawińska E. (2009). Business clusters in the development of competitiveness and innovation of regions, PWE, Warszawa. (in Polish) 